\title{
Article
}

\section{Cesium Adsorption Behavior of Vermiculite and It's Application to the Column Method}

\author{
Noriko SUZUKI*, Kotaro OCHI and Toshiyuki CHIKUMA \\ Analytical Chemistry of Medicine, Showa Pharm., Univ, Machida, Tokyo 194-8543 Japan
}

(Manuscript received June 30, 2014; Accepted August 6, 2014)

\begin{abstract}
The cesium adsorption behavior of vermiculite from a pure aqueous solution was studied in terms of the vermiculite grain size and reactant concentrations. Although a relation between grain size and the cesium adsorption percentage was not observed when the concentration of cesium in the reactant was high, the adsorption rate decreased at a certain grain size when cesium concentration was low. Reverse ion-exchange reactions were insignificant when water was used as an eluent.

Vermiculite with a grain size of 500-599 $\mu \mathrm{m}$ was used in the column method. As the flow rate increased, the breakthrough point decreased. Although a considerably low flow rate was required to obtain significant recovery of cesium from contaminated water, it is suggested that vermiculate with a relatively large grain size could be used in the column method.
\end{abstract}

Keywords: cesium uptake, ion exchange, gain size, vermiculite, column method

\section{Introduction}

The accident at the Fukushima Daiichi Nuclear Power Plant that occurred as a result of the huge tsunami following the Great East Japan Earthquake on March 11, 2011, caused the loss of all electric power. Seawater was used to cool the reactors, resulting in a large amount of radioactive contaminated seawater. In addition, hydrogen explosions and meltdowns in the reactors scattered radioactive substances into the surrounding area, which should be decontaminated before evacuated residents can return to their houses. Many residents in non-evacuated areas wanted to decontaminate their houses because the amount of radiation was higher than before the accident. A large amount of contaminated water was thereby generated because the decontamination was mainly performed by washing the houses with a high-pressure washing device. Radioactive elements should be removed both from contaminated water and seawater before reuse or drainage.

Although some zeolite and other materials are used as the adsorbents in the decontamination system at the Fukushima Daiichi Nuclear Power Plant, it is still useful to examine other adsorbents.

We have focused on vermiculite because it has a high cation-exchange capacity. As a possible mechanism for cesium adsorption by vermiculite is the ion-exchange reaction between $\mathrm{Cs}^{+}$in the reactant and the interlayer exchangeable cation of vermiculite, $\mathrm{Mg}^{2+}$, specific adsorption for large monocations, such as cesium, is poor compared to that for micas with frayed edges. Considering the supply aspect, vermiculite is a favorable material because it is a natural product. Much research has been conducted on vermiculite as a cesium adsorbent from radioactive waste since the early $1960 \mathrm{~s}^{1-5}$ In addition, it has been used as an adsorbent for cesium-137 in a column in a nuclear reactor laboratory. ${ }^{6}$ However, there have been no previous studies, except ours, ${ }^{7}$ regarding the grain size of vermiculite.

In this paper, we report the effect of grain size on cesium uptake by vermiculite according to the initial concentration of the reactant. In addition, the reverse ion-exchange behavior is described, and the results of the column method with vermiculite are discussed.

\footnotetext{
* Corresponding author

E-mail: n-suzuki@ac.shoyaku.ac.jp
} 


\section{Experimental}

\subsection{Reagents and Material}

Raw vermiculite (Hebei, China) as supplied was crushed in a powder mill and a mortar, and classified according to the required grain size fractions using sieves. A solution of cesium ions was prepared from regent-grade cesium chloride (Kanto Chemical Co., Japan). Ultrapure water (specific resistance 18.2 M $\Omega$ cm: PURIC Z-II, Organo Co., Ltd, Japan) was used in all experiments.

\subsection{Ion-exchange reaction}

Plastic containers were used in a batch method to avoid contamination due to sodium ions from glass vessels. The concentrations of the test solutions before and after the ionexchange experiments were determined using an atomic absorption spectrophotometer (Hitachi Z-2300). The cesium uptake rates were determined as follows: $0.2 \mathrm{~g}$ of vermiculite of a specified grain size was immersed in $20 \mathrm{~cm}^{3}$ of solutions containing $1.0 \mathrm{mmol} \mathrm{dm}{ }^{-3}, 10 \mathrm{mmol} \mathrm{dm}^{-3}$, and $50 \mathrm{mmol} \mathrm{dm}^{-3}$ of cesium ions. The sample containers were placed on a rotary shaker for $24 \mathrm{~h}$ at room temperature. The reaction time was determined from our previous study. ${ }^{7}$ The vermiculite after the reaction was dried for use in reverse ion-exchange tests. Ultrapure water and $3.0 \mathrm{~mol} \mathrm{dm}^{-3}$ of nitric acid were used as eluents.

\subsection{Column method}

Vermiculite with a grain size of 500-599 $\mu \mathrm{m}$ was used in the column method. A 1.0-g vermiculite sample was chosen in an ion-exchange column (I.D. $10 \mathrm{~mm}$ ). The reactant concentration was set at $1.0 \mathrm{mmol} \mathrm{dm}{ }^{-3}$, and several different flow rates were examined. The reactant of slightly more than $100 \mathrm{~cm}^{3}$ was applied to the column and the eluate was collected by $10 \mathrm{~cm}^{3}$-fraction. The concentration of each portion was determined by atomic absorption spectrophotometry.

\section{Results and discussion}

Figure 1 shows the relationship between grain size and percentage of cesium uptake from pure aqueous solutions. The cesium uptake rate was estimated using the following formula.

$$
\begin{aligned}
& \text { Cs uptake rate }(\%)= \\
& \frac{\text { (Initial conc. of reactant)-(Conc. of supernatant) }}{\text { Initial conc. of reactant }} \times 100
\end{aligned}
$$

The adsorption rates for high concentrations of $\mathrm{CsCl}$ were low, and little difference in the adsorption rates was observed for all particle sizes. Because the ion-exchange capacity of vermiculite has been reported as $100-150 \mathrm{meq} / 100 \mathrm{~g},{ }^{8}$ the maximum amount of exchanged cesium on $0.2 \mathrm{~g}$ of vermiculite is $0.2-0.3 \mathrm{mmol}$. Meanwhile, the amount of cesium in $20 \mathrm{~cm}^{3}$ of $1.0 \mathrm{mmol} \mathrm{dm}^{-3}, 10 \mathrm{mmol} \mathrm{dm}^{-3}$ and $50 \mathrm{mmol} \mathrm{dm}^{-3}$ reactants are $0.02 \mathrm{mmol}, 0.20 \mathrm{mmol}$ and $1.0 \mathrm{mmol}$, respectively. The adsorption rate for the reactant of $50 \mathrm{mmol} \mathrm{dm}^{-3} \mathrm{CsCl}$ was about $20 \%$, that is well correspond to the theoretical value. In case of the $10 \mathrm{mmol} \mathrm{dm}^{-3} \mathrm{CsCl}$ reactant, the experimental data showed less adsorption rate compare to the theoretical one. To elucidate this phenomenon, the effect of other experimental parameters such as ionic strength should be studied. In subsequent experiments, we did not use these high concentrations, as useful results would not be obtained. In contrast, a favorable result was obtained when the concentration of the reactant was low, even with large-size vermiculite. In addition, the adsorption rates were distinctly different between size fractions $1000-1400 \mu \mathrm{m}$ and $1400-1700 \mu \mathrm{m}$ at low $\mathrm{CsCl}$ concentrations. In general, smaller particles are superior to larger ones in terms of ion-exchange capability because of their larger surface area to volume ratio. In contrast, our results showed that all grains smaller than a certain size gave the same results for the ion-exchange rate as shown in Fig. 1. As

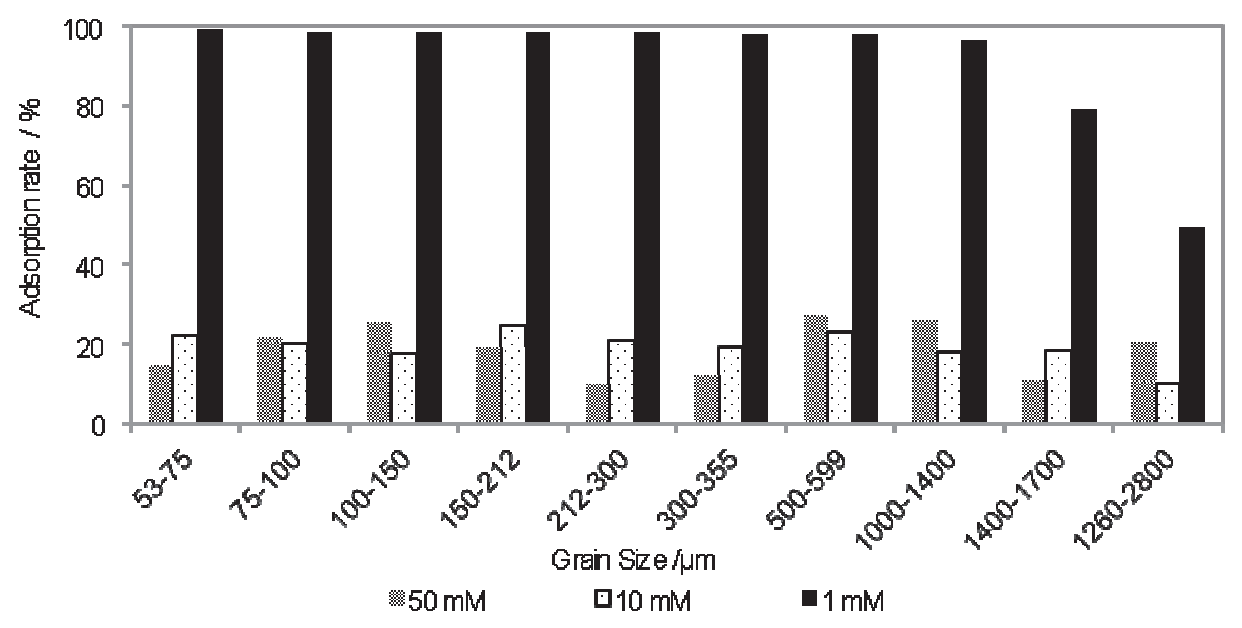

Fig. 1 Effect of grain size on Cs uptake.

A-B on the abscissa axis means that the grains passed through a sieve with mesh size $B$ and gathered on a sieve with mesh size $A$. The concentrations are those of the cesium chloride solutions used. 
mentioned above, there was a large difference between the adsorption rate for 1000-1400 $\mu \mathrm{m}$ and $1400-1700 \mu \mathrm{m}$; however, we decided to use the size 500-599 $\mu \mathrm{m}$ for the remaining experiments because there was a slight difference between sizes 1000-1400 $\mu \mathrm{m}$ and 500-599 $\mu \mathrm{m}$.

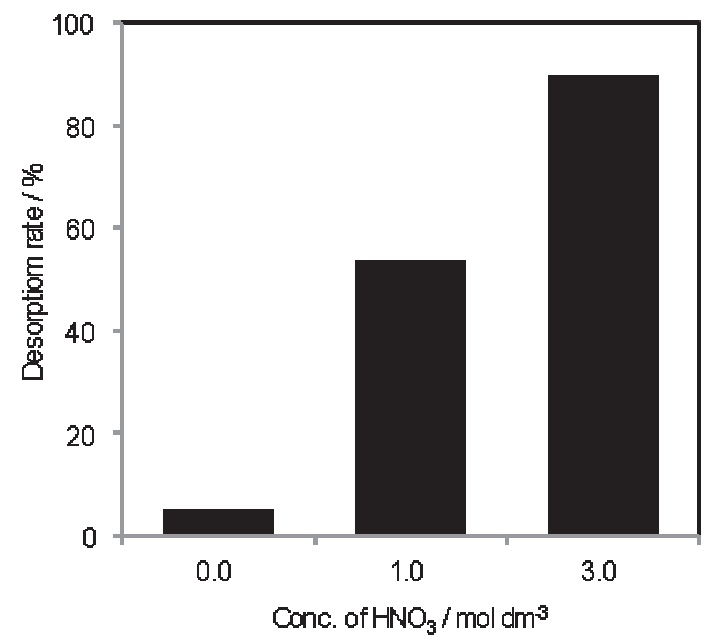

Fig. 2 Desorption rate.

Initial concentration of Cs: $10 \mathrm{mmol} \mathrm{dm}^{-3}$,

mass of Cs-vermiculite: $0.2 \mathrm{~g}$, volume of eluent: $20 \mathrm{~cm}^{3}$.

Desorption tests were conducted to confirm whether the cesium ions were fixed safely on the vermiculite after adsorption. Different concentrations of nitric acid were used as eluents. Desorption rates became higher as the concentration of nitric acid rose, as shown in Fig. 2. Thus, it is clear that desorption had truly occurred during the ionexchange reaction. In regard to the other cations, Kogure et al. reported that intercalated $\mathrm{Cs}^{+}$was hardly removed by simple ion-exchange reaction with external trivalent cations, ${ }^{9}$ and
Morimoto et al. published a paper about desorption of adsorbed $\mathrm{Cs}+$ in vermiculite by $3.0 \mathrm{~mol} \mathrm{dm}{ }^{-3}$ aqueous $\mathrm{Mg}\left(\mathrm{NO}_{3}\right)_{2}{ }^{10}$ Our experimental result and these reports suggest that the vermiculite can be safely stored after use, unless it is exposed to strongly acidic conditions or to contact with the high concentration of magnesium solution. However, only approximately $5 \%$ of uptake cesium was desorbed when water was used as an eluent. To ensure safe storage, all of the cesium must be kept inside the vermiculite after adsorption. Further investigation is required to solve this problem, and to store vermiculite more safely after use. Desorption of cesium by the strong acid is the disadvantage with the aspect on the safe storage, however, it is possible to consider the process of storing with volume reduction by the concentration after the ionexchanged cesium is eluted with strong acid from the vermiculite.

From our previous study, small particles of vermiculite reached their maximum adsorption of cesium faster than larger ones. ${ }^{7} \quad$ Use of this vermiculite for the column method, however, required a long processing time, and there is a possibility that the column could become clogged. For these reasons, the grain size 500-599 $\mu \mathrm{m}$ was used for the column method. The cesium adsorption rate of vermiculite by the column method is shown in Fig. 3. The initial concentration of the reactants was set at $1.0 \mathrm{mmol} \mathrm{dm}^{-3}$, because these reactants showed $90 \%$ or more adsorption rates using the batch method. One liter of cesium solution could be treated at this concentration in theory assuming an ion-exchange capacity of $100 \mathrm{meq} / 100 \mathrm{~g}$. In contrast to this, our result shows a breakthrough point at an early stage, particularly at a flow rate of $5.0 \mathrm{~cm}^{3} / \mathrm{min}$, which is one drop per second. The disadvantage of the inorganic ionexchanger compared with organic ones such as the ionexchange resin is the slow reaction rate; thus, it is necessary to

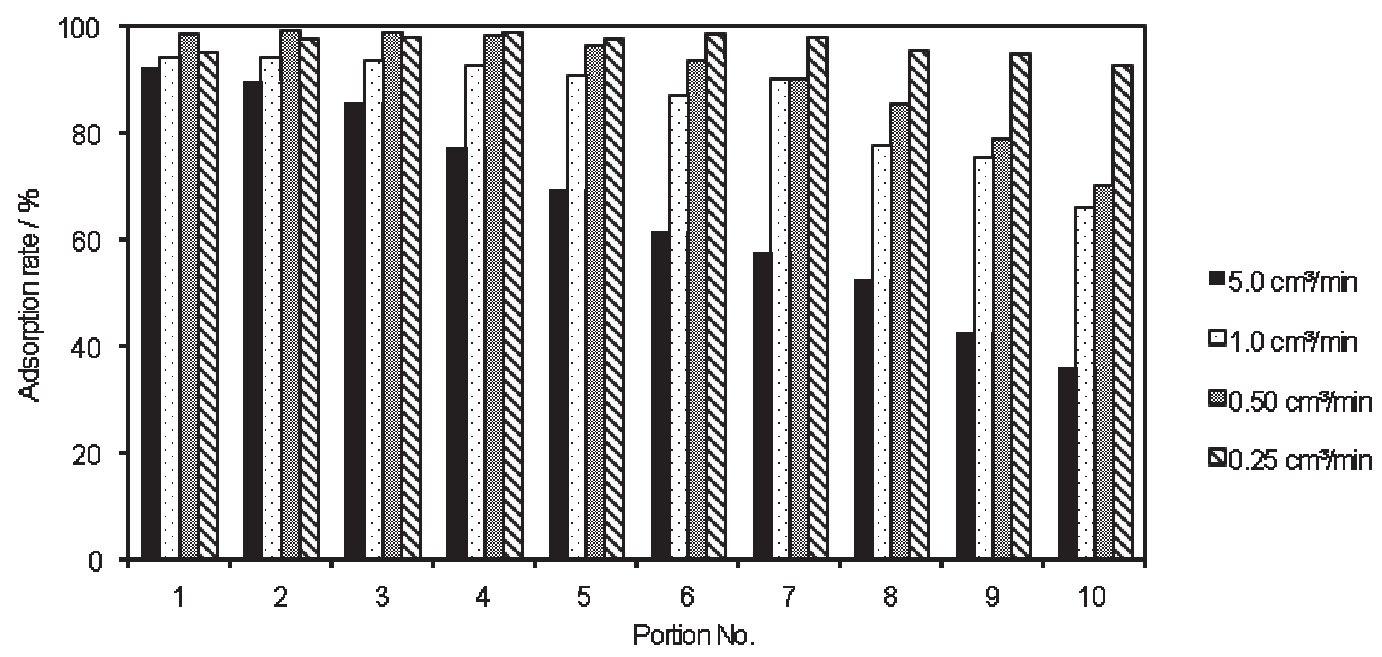

Fig. 3 Adsorption rates by the column method.

The initial concentration of reactant was set at $1.0 \mathrm{mmol} \mathrm{dm}^{-3}$. The eluate was batched off in $10 \mathrm{~cm}^{3}$ portions, numbered 1 to 10 . 
slow down the flow rate considerably, e.g., to $0.25 \mathrm{~cm}^{3} / \mathrm{min}$, as shown in Fig. 3. Approximately $93 \%$ of cesium was collected by Portion number 10 at this flow rate. This is the same as the result by the batch method with a reaction time of $24 \mathrm{~h}$, the initial concentration of $1.0 \mathrm{mmol} \mathrm{dm}^{-3}$ and the grain size 500 $599 \mu \mathrm{m}$.

In conclusion, although some modifications are needed with respect to the flow rate, our demonstration indicates that the column method with relatively large particles of vermiculite is effective for recovery of cesium from aqueous solutions.

\section{References}

1) B. L. Sawhney, Soil Sci. Soc. Proc., 28, 183-186 (1964).
2) B. L. Sawhney, Soil Sci. Soc. Proc., 29, 25-28 (1965).

3) B. L. Sawhney, Soil Sci. Soc. Proc., 30, 565-569 (1966).

4) B. L. Sawhney, Clays Clay Minerals, 20, 93-100 (1972).

5) C. A. Sikalikis, P. Misaelides, and C. A. Alexiades, Environ. Pollut., 52, 67-79 (1988).

6) A. Koyama, and K. Nishimaki, Mizu Shori Gijutu, 37, 499505 (1996).

7) N. Suzuki, S. Ozawa, K. Ochi, and T. Chikuma, J. Chem. Technol. Biotechnol., 88, 1603-1605 (2013).

8) T. Sato, NENDO KAGAKU, 41, 26-33 (2001).

9) T. Kogure, K. Morimoto, K. Tamura, H. Sato, and A. Yamagishi, Chem. Lett., 41, 380-382 (2012).

10) K. Morimoto, T. Kogure, K. Tamura, S. Tomofuji, A. Yamagishi, and H. Sato, Chem. Lett., 41, 1715-1717 (2012). 